\title{
Sexual and Gender-Based Violence: To Tweet or not to Tweet?
}

\author{
Alexandra Masciantonio ${ }^{1}$, Sandy Schumann², \& David Bourguignon ${ }^{1}$ \\ ${ }^{1}$ University of Lorraine, Nancy, France \\ 2 University College London, London, United Kingdom
}

\begin{abstract}
This research explores the reasons that lead survivors of sexual and gender-based violence to share their experiences on Twitter, as well as the reasons that prevent them from doing so. Using an online survey, we investigated the perspective of 94 survivors of sexual and gender-based violence. Open-ended responses were analysed with the ALCESTE method, a lexical analysis. Considering that in-person self-disclosure differs from inpublic self-disclosure, we based our interpretations of the findings on self-disclosure as well as collective action and social activism frameworks. Results showed that those who shared their experience on Twitter did so to render sexual and gender-based violence more visible, and to support the \#MeToo movement. They also wanted to change public perceptions of sexual and gender-based violence, while addressing violence at work and denouncing rape culture (the difficulty of filing a complaint, and victim blaming). On the contrary, survivors who did not tweet their experience expressed several concerns, such as feeling ashamed, the fear of being judged by others, and a lack of trust in the Twitter platform and its members. This research concludes that in order to understand the disclosure of victimisation on social network sites, like Twitter, it is worthwhile to complement the self-disclosure framework with insights on collective action and social activism. We also make a call for taking into account differences of social network sites when studying online disclosure of sexual and gender-based violence. Content warning: This article discusses issues of sexual and gender-based violence.
\end{abstract}

Keywords: Twitter; sexual and gender-based violence; self-disclosure; collective action; social network sites

\section{Introduction}

Sexual and gender-based violence is a form of "violence that is targeted at women or men because of their sex and/or their socially constructed gender roles"; it can manifest as humiliation, discrimination, street harassment, sexual assault, or rape (Carpenter, 2006, p. 83). Previous research has shown that the survivors of sexual abuse are unable or unwilling to reveal what they have experienced immediately to others (Finkelhor et al., 1990). Similarly, women, frequently do not dare to respond to sexism and gender-based remarks they are confronted with in public (Swim \& Hyers, 1999). However, the potential consequences of sexual and gender-based violence depression, sleep disorders, loss of self-esteem, or suicidal thoughts - may be partly alleviated by receiving emotional and informational support (Starzynski et al., 2005). Disclosing experiences of sexual and gender-based violence is therefore strenuous for survivors, but could be beneficial for their recovery.

In recent years, social network sites have provided alternative spaces for survivors' voices. One example is the movement \#NotOkey, initiated by Kelly Oxford in October 2016. In response to the sexist discourse of Donald Trump, she encouraged women all over the world to tweet their experiences of assault. Bogen et al. (2018) have explored the content of these messages of disclosure; survivors addressed the type of assault, its location, described the perpetrator and their tactics, mentioned their age at the time, their beliefs about the assault, and, 
finally, the emotional consequences. On this last point, as Stenberg (2018) indicated, \#NotOkey offered a collective space for survivors where their shame was transformed, evolving from an individual's to a cultural emotion. It must be noted that many tweets using the hashtag \#NotOkey were also reactions to these messages of disclosure (Bogen, Bleiweiss, \& Orchowski, 2019): positive reactions (advocacy, emotional support, informational aid, taking responsibility for change) were more prevalent that negative ones (distracting and egocentrism).

\#NotOkay was not the only case where a large movement of disclosures of sexual and gender-based violence spread rapidly through social network sites. Another well-known example is the call from Alyssa Milano, following the Harvey Weinstein affair in October 2017, to share experiences of sexual and gender-based violence on Twitter, using the \#MeToo hashtag (first proposed by Tarana Burke; Onwuachi-Willig, 2018). There is evidence to suggest that, similarly to \#NotOkay, social network sites provided relevant spaces where survivors could break the silence and connect to others (Bogen, Bleiweiss, Leach, et al., 2019). Notably, survivors disclosed their experience in different ways, depending on the platform they used: posts on Reddit were focused on in-depth descriptions of sexual assault in families and at the workplace; Twitter users encouraged others to continue the movement and showed empathy with survivors (Manikonda et al., 2018). However, despite the aforementioned tweet analyses, few studies have explored practices of sharing sexual and gender-based violence on social network sites from the survivors' perspective. Specifically, little is known about the survivors' motivations for disclosure as well as potential reasons for non-disclosing sexual and gender-based violence on social network sites.

Considering the importance of disclosure for survivors (Starzynski et al., 2005), this research aims to answer two main questions: why do some survivors decide to share their experience of sexual and gender-based violence on social network sites? And, why do others not take the leap? To address these, we conducted a qualitative online survey, focusing on reports of sexual and gender-based violence on Twitter. Survivors provided in free-text answers reasons for tweeting their experiences, as well as reasons for deciding to keep this information to themselves. Answers were analysed with the ALCESTE method. To interpret our results, different disciplines (i.e., psychology, communication, human-computer interaction, and feminist studies) as well as different fields of research have to be integrated. Indeed, in-public self-disclosure deviates from in-person self-disclosure: the social context is preponderant, and survivors can seize self-disclosure as a means for social activism (Gueta et al., 2020). We therefore argue that the prominent literature on self-disclosure, even if it includes to some extent societal motivations (Andalibi \& Forte, 2018; Chaudoir \& Fisher, 2010), will benefit from an extension, in particular, from insights proposed in research on collective action and social activism.

\section{Self-Disclosure Framework}

Self-disclosure corresponds to "what individuals voluntarily and intentionally reveal about themselves to others including thoughts, feelings and experiences" (Posey et al., 2010, p. 183). In psychology, the Disclosure Processes Model (DPM; Chaudoir \& Fisher, 2010) aims at understanding both disclosure decision-making and post-disclosure outcomes. The DPM argues that before making any decision, people anticipate the goals of self-disclosing. These goals can be distinguished according to people's motivations: pursuing a desired or positive state (i.e., approach goals; e.g., gaining hopefulness, intimacy, acceptance, ...) or avoiding an undesired or negative state (i.e., avoidance goals; e.g., preventing social rejection, anxiety, social distancing, ...). The DPM also considers reactions of the confidant, which can be supportive or not, and characteristics of the disclosed information (depth, breadth, duration, and emotional content). Disclosure outcomes take into account the individual (psychological and physical well-being), the dyad (intimacy and trust), and the social context (norms and stigmata). One advantage of the DPM is to highlight how the consequences of an act of disclosure can affect future disclosure decision-making and post-disclosure outcomes.

Although the DMP pertains to in-person disclosure, Gueta et al. (2020) have explored how it can inform disclosure of sexual assaults on various social media. Through 14 interviews with Israeli women, they indicated two main motivations to self-disclose online: generate social change and help other survivors. Moreover, the authors illustrated that public self-disclosure can have both positive (reframing the sexual-assault narrative, improving interpersonal relationships, and reconstructing the identity from that of a victim, to that of a strong feminist activist) and negative outcomes (feelings of revictimisation). As noted previously, they finally concluded that inpublic self-disclosure is a context-dependent process, differing on that point from in-person self-disclosure. 
Another relevant framework for understanding why people decide to disclose sexual and gender-based violence on social network sites can be found in communication and human-computer interaction studies. The Disclosure Decision-Making model (DDM; Andalibi \& Forte, 2018) is based on work that has demonstrated that social network sites where users remain anonymous (i.e., Reddit) protect survivors from the potentially negative consequences of public exposure, therefore enabling them to self-disclose and to seek social support (Andalibi et al., 2016). The DDM proposes that self-disclosure on social network sites where people are identifiable (i.e., Facebook) is shaped by six factors: self-related (e.g., reframing the narrative, finding social support, ...), audience-related (e.g., avoiding unwanted conversations, ...), network-level, societal (e.g., fighting against the stigma, ...), temporal (e.g., time passing facilitates disclosure, ...), and lastly, platform-related (e.g., anonymity, asynchronous communications, ...). Concerning the network-level, the DDM introduces the concept of network-related reciprocal disclosure; it is unique to social media and refers to the fact that seeing others self-disclose on social network sites encourages stigmatised people to do the same because the perceived stigma is reduced. One further advantage of the DDM is that these six factors may explain both the disclosure of distressing experiences and non-disclosure (Andalibi, 2020).

Gallagher et al. (2019) analysed more than 1.8 million \#MeToo tweets, relying both on the DDM model and feminist studies. They found evidence for the network-related reciprocal disclosure: when a survivor self-disclosed, there were subsequently more disclosures from their followers. Furthermore, the more disclosures survivors had seen before they self-disclosed, the more likely they were to provide in-depth descriptions of their sexual and genderbased experience. This study is, to the best of our knowledge, the first to establish a connection between the selfdisclosure and social activism frameworks, demonstrating the necessity to extend the conceptualization of disclosure of sexual and gender-based violence on social network sites.

\section{Collective Action and Social Activism Frameworks}

The Disclosure Processes Model (Chaudoir \& Fisher, 2010) provides information on the successive steps leading survivors to share their experience with someone and its multilevel outcomes. But, as Gueta et al. (2020) concluded, in-public self-disclosure differs from in-person self-disclosure by being a context-dependent process. The Disclosure-Making model (Andalibi \& Forte, 2018) identifies the main reasons motivating survivors to reveal on social network sites. However, the DMM has mostly relied on pregnancy loss disclosures on Facebook. Facebook is a relatively closed social network site with a known audience, which is not the case for other social network sites like Twitter. Pregnancy loss is a stigmatising experience but - in absence of third parties who inflicted the loss - women are likely to attribute responsibility to themselves. It is, therefore, more difficult to develop a shared group identity and act collectively. Consequently, it is not surprising that Andalibi \& Forte's work did not reveal dominant collective action motives. To argue why it is important to consider the latter, we will first introduce the concept of rape culture which sheds light on the social context surrounding sexual and gender-based violence. Second, we will clarify how survivors can act collectively on social network sites and use their personal experience to respond to the rape culture.

When survivors disclose sexual and gender-based violence, others may minimise the importance of the event, criticise and blame the survivor, or avoid contact (Davis \& Brickman, 1996). These negative reactions are embedded in a social context, which is known as rape culture (Lonsway \& Fitzgerald, 1995). Rape culture is associated with myths about rape, "attitudes and beliefs that are generally false but are widely and persistently held, and that serve to deny and justify male sexual aggression against women" (Lonsway \& Fitzgerald, 1994, p. 134). "Women lie about rape", "most of the rapes are committed by strangers with a weapon", or "it is impossible to rape an intimate partner" are few examples. Besides justifying rape, the rape myths also blame survivors (i.e., victim blaming; Suarez \& Gadalla, 2010).

Survivors' feelings of responsibility and anticipation of being blamed, judged, or not believed, impede the disclosure (Alaggia, 2005). Social network sites, however, has given survivors a powerful tool to realise that they are not alone and, subsequently, challenge rape culture collectively (Wright et al., 1990, p. 995). In this context, the concept of hashtag feminism has been introduced, "a form of feminist activism that appropriates Twitter's metadata tags for organizing posts and public-by-default nature to draw visibility to a particular cause or experience" (Clark-Parsons, 2021, p. 362). 
The \#MeToo movement, for instance, allowed survivors of sexual and gender-based violence to engage in a politic of visibility (Clark-Parsons, 2021). By rendering their personal experience visible, survivors deconstructed the dominant discourse of rape culture and contested existing social norms. Here, the action that is taken on behalf of a wider group - based on a shared identity - is expressed through personal action frames, on social network sites. Formal membership in an organisation is not required and participation is not guided by centralised institutions. Collective action, as discussed in this paper, can therefore be considered as following the logic of connective action (Bennett \& Segerberg, 2012; Papacharissi, 2016). Survivors also adapted to the limitations of hashtag feminism (e.g., revictimisation, exclusion of other minorities, trauma re-experience) by developing performance maintenance practices: expressing interpersonal solidarity, sharing resources, creating preventive tweets, or defending other survivors (Clark-Parsons, 2021). Notably, the responses on social network sites constitute a politic of care: by sharing their stories of sexual and gender-based violence, survivors enhance the capacity of other survivors to do the same (Rentschler, 2014). Further evidence for an affective and supportive feminist culture on social network sites was identified by Keller et al. (2018). They combined interviews with observations of the website Hollaback! and the \#BeenRapedNeverReported tweets, and demonstrated how social media provided opportunities to build a community, while challenging the rape culture.

In order to better understand disclosure of sexual and gender-based on social network sites as collective action, it is worthwhile to draw in psychology on the Social Identity Model of Deindividuation Effects (SIDE; Lea \& Spears, 1991). SIDE argues that online interactions can increase the salience of shared group identities (i.e., cognitive component; Lea \& Spears, 1991; Postmes et al., 1998; Spears, 2017). For instance, disclosing experiences of sexual and gender-based violence on social media "allowed [survivors] to engage in a process of identity reconstruction, from one of a controlled, fragile, and insignificant victim, to that of a feminist activist and influencer who is in control, safe, powerful, and significant" (Gueta et al., 2020, p. 630). Moreover, once their group identity is salient, people are more likely to behave in line with and express group norms (i.e., strategic component; Spears, 2017). This behaviour can serve identity confirmation and identity mobilisation (Klein et al., 2007). The former refers to the assertion and celebration of the group identity, which confirms one's identity as a group member. The latter aims at improving the position of the group in society by mobilising the in-group and attempting to convince the outgroup to support their cause.

SIDE offers an alternative framework to comprehend hashtag feminist studies. As stated earlier, the disclosure of sexual and gender-based violence on social network sites can represent both a politic of care and a politic of visibility (Clark-Parsons, 2021; Rentschler, 2014). These politics resonate with the SIDE's strategic component. Like the identity confirmation function, the politic of care concentrates on the group of survivors of sexual and genderbased violence, supporting them and enhancing their capacity to self-disclose. The politic of visibility makes sexual and gender-based violence visible to everybody with the intent to change society, which resembles the function of identify mobilisation.

To conclude, collective action and social activism frameworks emphasise the social context of sexual and genderbased violence, notably rape culture. Specifically, the frameworks stipulate that survivors' disclosure can challenge the interpretations of everyday violence and mobilise against a systemic injustice. When survivors decide to disclose their experience of sexual and gender-based violence in-public rather than in-person, there remains to understand the extent to which it is a context-dependent process (Gueta et al., 2020). Consequently, the literature still needs to establish a connection between the self-disclosure framework and the collective action and social activism frameworks.

\section{The Current Research}

The current research aims to identify both the reasons that lead survivors of sexual and gender-based violence to share their experiences on social network sites, as well as the reasons that prevent them from doing so. We grounded the interpretation of the results on the reviewed literature, that is, self-disclosure and collective action and social activism frameworks. We combined different models (Andalibi \& Forte, 2018; Chaudoir \& Fisher, 2010; Clark-Parsons, 2021; Klein et al., 2007; Rentschler, 2014) to reflect on how these overlap and complement each other. Indeed, given recent studies that demonstrated the overall importance of societal motivations in the disclosure of sexual and gender-based violence on social network sites (Gallagher et al., 2019; Gueta et al., 2020), one additional objective was to investigate if the current self-disclosure framework should be extended by 
including insights from collective action and social activism frameworks. Our analyses sought to answer three research questions:

RQ1: Why do survivors decide to share their experience of sexual and gender-based violence on Twitter?

RQ2: Why do survivors decide to not share their experience of sexual and gender-based violence on Twitter?

RQ3: Under what circumstances and to what extent would it be beneficial to extend the self-disclosure framework with insights from collective action and social activism frameworks to enhance the understanding of disclosures of sexual and gender-based violence on social network sites?

We focused our research on Twitter. In addition to having been the incubator of the \#MeToo and \#NotOkay movements, Twitter is one of the most used social platforms in the world (Similarweb, 2019). Our research was also conducted in France, where less than $3 \%$ of survivors dare to make a complaint about sexual and genderbased violence (Bousquet et al., 2019). The \#MeToo movement began in France shortly after the call from Alyssa Milano. A New-York based French journalist, named Sandra Muller, invited French people to be part of the movement with the hashtag \#BalanceTonPorc (that is to say, \#DenounceYourPig), and to share the names of their perpetrators (Donadio, 2017). Criticism was raised immediately: a few months after, 100 influential French women signed an open letter to contest the movement (Collective, 2018). In September 2019, Sandra Muller was convicted for defamation, highlighting the complex situation of reporting sexual and gender-based in France (Tenaglia, 2019).

\section{Method}

\section{Procedure}

This study was part of a wider research project on the predictors of sharing incidents of discrimination on Twitter. Participation was voluntary and all participants signed an informed consent form. An anonymous online questionnaire was created in French using the LimeSurvey software. The hypertext link, which enabled the participants to access this questionnaire, was tweeted via the researchers' Twitter accounts. This procedure has already been used in other studies (Andalibi \& Forte, 2018; Gueta et al., 2020). The use of a convenience sampling method is justified in this qualitative research because it aims at refining and exploring, rather than testing, theories (Djafarova \& Rushworth, 2017). Data collection was carried out from 6th January 2019 to 11 th February 2019.

\section{Measures}

We first verified, with two questions, whether participants had a Twitter account and had experienced sexual and gender-based violence. Then, participants estimated the time that had passed since this event (less than 3 months, from 3 to 6 months, from 6 months to 1 year, from 1 to 2 years, from 2 to 5 years, from 5 to 10 years, more than 10 years). They also specified whether they had shared this violence on Twitter, and if this was the case, if they had used the \#MeToo hashtag or its French version, \#BalanceTonPorc. Finally, if participants declared having tweeted about their stories, they were encouraged to answer this open question: "Why did you decide to share on Twitter the gender-based and sexual violence you experienced?" Those who answered not having shared their victimisation on Twitter were asked: "Why did you not want to share on Twitter the gender-based and sexual violence you experienced?" Doing so, two corpuses of answers were obtained which were subject of two separate analyses that applied the ALCESTE method. Since participants responded in French, the analyses were also carried out in French. The results were then translated into English by a professional translator.

\section{Sample}

Ninety-four people who self-reported being survivors of sexual and gender-based violence agreed to take part in this research ( 88 women, 4 men and 2 people having a gender identity other than male or female). The unequal gender distribution may reflect men's difficulty to recognise and accept the sexual abuses they have experienced, 
particularly due to a number of sociocultural factors (Alaggia, 2005; Hlavka, 2017). The participants' age ranged between 18 and $62(M=28.23, S D=9.11)$. As to their life situation, 40 participants were student, 38 had a professional activity, 8 were unemployed, and 8 were in another situation. Eight participants had filed claims for sexual and gender-based violence to the court. Two sub-samples were created based on whether the survivors had shared their stories on Twitter or not (Table 1).

Table 1. Distribution of the Two Sub-Samples According to Gender, Life Situation, Age, the Filing of the Complaint to the Court, and the Use of \#MeToo or \#BalanceTonPorc Hashtags.

\begin{tabular}{|c|c|c|}
\hline & Sub-sample one: & Sub-sample two: \\
\hline & $\begin{array}{c}\text { have tweeted about sexual and } \\
\text { gender-based violence }\end{array}$ & $\begin{array}{c}\text { did not tweet about sexual and } \\
\text { gender-based violence }\end{array}$ \\
\hline \multicolumn{3}{|l|}{ Gender } \\
\hline Woman & 27 & 61 \\
\hline Man & 1 & 3 \\
\hline Other identity & 1 & 1 \\
\hline \multicolumn{3}{|l|}{ Life situation } \\
\hline Students & 6 & 34 \\
\hline Workers & 15 & 23 \\
\hline Unemployed & 4 & 4 \\
\hline \multirow[t]{2}{*}{ Other situation } & 4 & 4 \\
\hline & $18-52$ & $18-62$ \\
\hline Age & $(M=31.79, S D=8.79)$ & $(M=26.65, S D=8.86)$ \\
\hline Complaint filed to the court & 5 & 3 \\
\hline \#MeToo or \#BalanceTonPorc use & 15 & \\
\hline
\end{tabular}

\section{ALCESTE Method}

To investigate our research questions, we employed a lexical analysis: the ALCESTE method (Reinert, 1983, 1986, 1987). Since the literature on disclosure of sexual and gender-based violence is largely based on thematic analyses, our goal was to assess if alternative methodologies can - or not - add new insights. In addition, ALCESTE has several advantages. The method is blind to the meaning of the data; it thus can be considered as fully inductive, and all theoretical frameworks are in principle relevant when interpreting text. Consequently, the method is also "transparent and reproducible" (Schonhardt-Bailey et al., 2012, p. 510). If another researcher wants to re-do our analyses, they will find the same outputs. However, the interpretation of the ALCESTE's outputs has to be conducted by an expert who must provide contextual knowledge (Lahlou, 2011).

The idea behind the ALCESTE method is that words that are used together belong to the same context and expose what is called a lexical universe - a vocabulary specific to a theme, reflecting the speaker's thoughts. The analysis relies on a top-down hierarchical technique to classify textual data. Simply stated, it consists of computationally clustering sentences that contains words in close association (i.e., co-occurrence of words). Researchers can also include passive variables, like sociodemographic characteristics, which are not directly taken into account during the analysis. An example would be if an expert studied the speech of several politicians and specified their gender with a passive variable. The ALCESTE method will analyse these speeches based solely on the words used by the politicians, without considering their gender. But at the end of the analysis, the expert can identify if the politicians' gender is associated with some specific vocabulary (i.e., the classes extracted). Another important feature is lemmatization: full words - nouns, verbs, adjectives, and adverbs - are reduced to their root forms. When the classification is completed, researchers need to interpret the results which are presented as a series of classes. Several indicators may help this interpretation. For example, the links between the classes can be visualised into a dendrogram. In addition, a chi-square value is assigned for each word in the class: the higher the value, the stronger the association between the word and the class. Based on these chi-square values, fragments of sentences that best represent the class are also selected; these are called characteristic segments. For further and more detailed information, a full description of the ALCESTE method is presented in the Appendix of SchonhardtBailey et al. (2012). 
To apply the ALCESTE method to our data, we used the IraMuTeQ software (Ratinaud, 2009). Before conducting the analysis, spelling mistakes were corrected. Then dashes were added between the words "social" and "media", and between the words "real" and "life"; so that the software could process them as a sole unit. Finally, the following passive variables were included: participants' gender, the time that had passed since the sexual and gender-based violence, whether participants had filed a complaint to the court, and, lastly, the use of the \#MeToo or \#BalanceTonPorc hashtags.

\section{Results}

\section{Tweeting About Sexual and Gender-Based Violence}

Due to the fact that only 29 of 94 participants had disclosed their experience of sexual and gender-based violence experience on Twitter, the corpus of answers of this sub-group was small and the analysis extracted only two broad classes. Based on recommendations from Reinert (2002), we have therefore duplicated the corpus: the software analysed each term twice; which has not altered the data per se, but allowed a deeper analysis with more than two classes extracted. The final corpus consisted of 2442 occurrences (i.e., the total number of full words) and contained 394 reduced forms. A simple top-down hierarchical classification on text was carried out, and $68.97 \%$ of answers to the question "Why did you decide to share on Twitter the gender-based and sexual violence you experienced?" were classified. More precisely, six classes were extracted. We labelled them: give visibility to sexual and gender-based violence, support and contribute to the \#MeToo movement, talk about sexual and gender-based violence at work, change the public perceptions of sexual and gender-based violence, denounce the difficulty of filing a complaint, and overcome the victim blaming. As shown in the analysis' dendrogram (figure 1), we also labelled the associations between these classes. Below, the interpretations for each class are explained in more detail.

Figure 1. Dendrogram of the Top-Down Hierarchical Classification on the Reasons for Disclosing Sexual and Gender-Based Violence on Twitter.

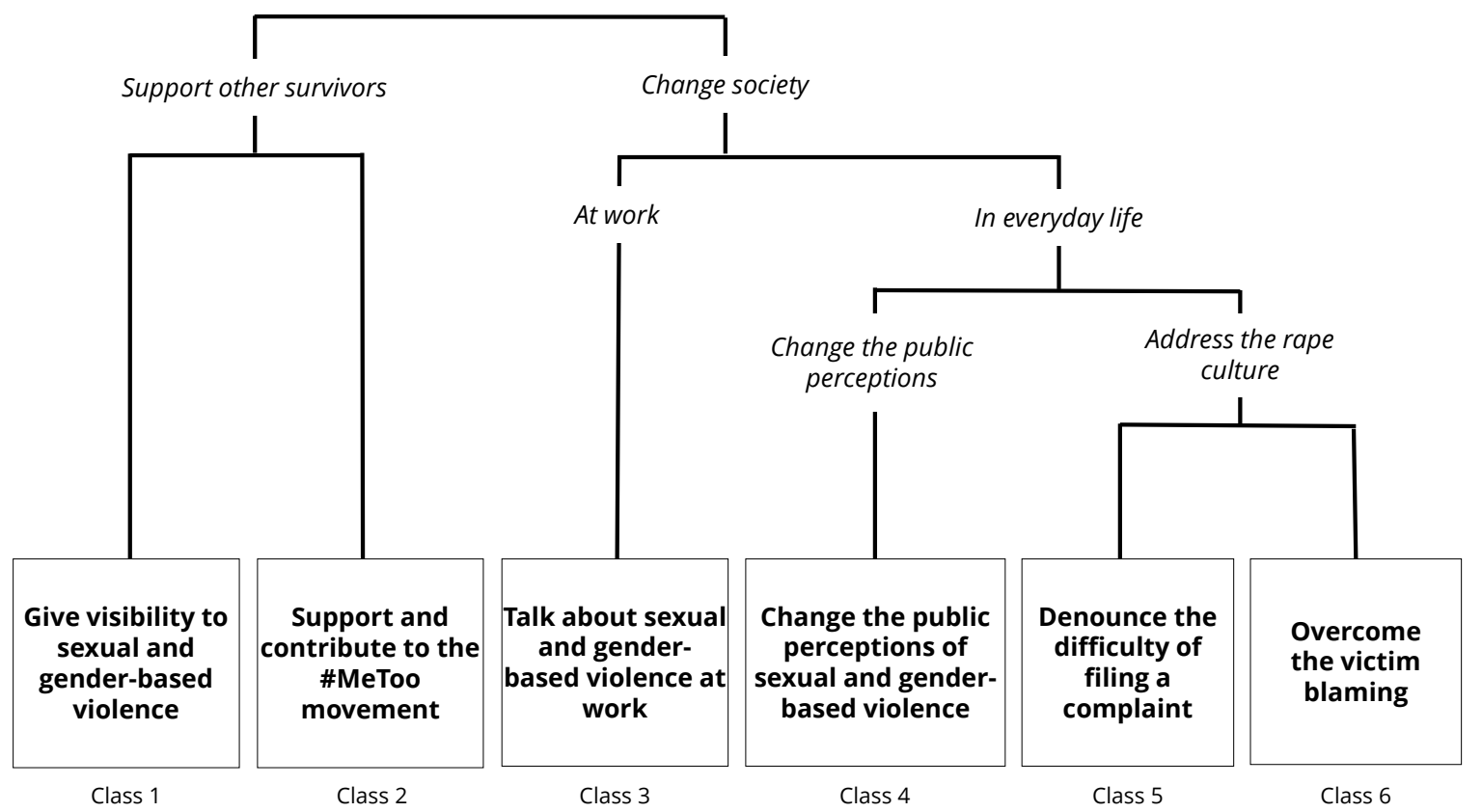

\section{Give Visibility to Sexual and Gender-Based Violence}

The words significantly associated with the class were (the chi-square values are in brackets): show (16.47), people (14.78), find (9.61), feel (4.27), raise (4.27), testimony (4.27), follow (4.27), necessary (4.27), number (4.27), and the passive variable indicating that the sexual and gender-based violence had occurred between 5 and 10 years ago (11.93). The discourse highlighted the importance of giving visibility to sexual and gender-based violence. Survivors 
aimed to raise awareness for the scope and ubiquity of this type of violence. A few characteristic segments are: "Because a lot of people did it. I felt it was legitimate to talk about what happened to me and I found that it was necessary to add my testimony to the others to show the number and frequency of this violence." and "To show that it happens to everyone, that doesn't just happen to others, and to raise the awareness of the people who follow me that it is a current situation and that it can happen to anybody and sometimes to people close to you without you knowing it. Show people the situations that we find abnormal."

\section{Support and Contribute to the \#MeToo Movement}

The words significantly associated with the class were: balancetonporc (25.19), situation (14.78), metoo (14.78), want (9.61), feel (4.27), support (4.27), number (4.27), appear (4.27), and the passive variable referring the use of the hashtags \#MeToo or \#BalanceTonPorc (5.78). The lexical universe conveyed the influence of the \#MeToo movement on survivors; it gave them courage to share their story, which they did using the \#MeToo or \#BalanceTonPorc hashtags. Survivors sought to make a contribution to the movement and wanted to support and encourage other survivors. A few characteristic segments: "When \#metoo and \#BalanceTonPorc appeared, I supported on twitter people who had the same fear and situation as mine: people who had hesitated to testify because there is 'much worse'. That was what triggered it for me: I also had to testify, and add my even insignificant strength to this number, and fight against my feeling of being illegitimate." and "Because I felt driven by \#metoo and \#balancetonporc, I wanted to show the other potential victims that they are not alone."

\section{Talk About Sexual and Gender-Based Violence at Work}

The words significantly associated with the class were: research (25.19), environment (25.19), report (14.78), want (9.61), work (4.27), follow (4.27), support (4.27), and anger (4.27). The passive variable referring to the time since the sexual and gender-based violence had happened - between 3 and 6 months ago - was also significantly associated with the class (11.93). The lexical universe conveyed the need to denounce the sexual and genderbased violence taking place in the professional environment. The discourse dealt with the impunity of aggressors at work, aggressors whose responsibility is often removed, and violence that is made invisible. The following are characteristic segments for this class: "During a discussion on work conditions and how those who inflict and those who experience are treated. I wanted to report this injustice. I launched into it without thinking. It was to report the fact that aggressors in the work environment are easily supported." and "A solely verbal violence with no great consequences, but in a professional context: to testify to the triviality of sexism (and the social stigma of obesity specifically) in the research community."

\section{Change Public Perceptions of Sexual and Gender-Based Violence}

The words significantly associated with the class were: see (28.24), change (18.91), file (17.78), sort (17.78), society (17.78), reason (17.78), end (17.78), try (17.78), complain (9.61), thing (9.61), and the passive variables indicating that participants have a gender identity other than female or male (8.42) and that between 1 month and 1 year have passed since the event (8.42). The lexical universe pointed to the will to help move things forward, to change the perception and the treatment of sexual and gender-based violence in society. Survivors wanted to put an end to the impunity of aggressors and to do this, they tried to encourage other victims to speak out about what they have experienced. One characteristic segment: "Because we have to talk about it to try to change mentalities. Roughly, I see women being harassed and men with fragile egos not seeing the problem. Society as a whole must change, and I hope that if we report every day the aggressions we experience daily, men will end up understanding and changing."

\section{Denounce the Difficulty of Filing a Complaint}

The words significantly associated with the class were: share (25.19), file (15.19), condemn (25.19), victim (16.47), rapist (14.78), rape (14.78), justice (14.78), story (14.78), need (14.78), work (4.27), management (4.27), so (4.27), send (4.27), encourage (4.27), appear (4.27), and the passive variables indicating that survivors had filed a complaint to the court (28.24) and used the \#MeToo or \#BalanceTonPorc hashtags (5.78). The discourse of this class reflected the need to denounce the difficulties related to the complaint for acts of sexual and gender-based violence. Survivors whose answers were represented in this class were people who had filed a complaint in court. 
They expressed having experienced difficulties associated with convicting the aggressor, and they wanted to bring to light the mismanagement of survivors in the current justice system. One characteristic segment: "To share what I experienced, to encourage other victims to break the silence, to also show that the aggressor, a doctor, is free despite the two legal proceedings (and yes when you are the victim of a doctor there are two procedures). And show that filing a complaint it not enough to send the aggressor to jail, if only it was the case! There is very little justice in France. $2 \%$ of the rapists are convicted... and also to share the reality of the management of the victims, in my case: a judicial and therapeutical catastrophe. And the need to evacuate it."

\section{Overcome the Victim Blaming}

The words significantly associated with the class were: use (17.78), sexual (9.61), shame (9.61), and the passive variable indicating that the sexual and gender-based violence had occurred less than 3 months ago (8.42). The lexical universe documented the cultural difficulty of overcoming feelings of shame and guilt associated with the experience of sexual and gender-based violence. Survivors highlighted the importance of not feeling ashamed. Some survivors managed to share their story with the help of alcohol. Others tried both to hold the aggressors accountable for their acts and to denounce the victim blaming. Some characteristic segments: "I used the \#WhylDidntReport a few months ago. Actually, if I'm being honest, I'd had too much to drink that evening, and I no longer had any of the filters that I had had since the time of the offence and which prevented me from talking (the shame, the position of empowerment of the aggressor, ...)." and "I am the vice chairman of an association for the victims of traumatic amnesia related to sexual violence experienced in childhood. We encourage the victims to talk so that the shame naturally changes sides. I had to do the same myself. Especially we are also fighting to get the law changed, and when we intervene in the national assembly or the senate, we also come with our stories. So mine is public to help our cause."

\section{Not Tweeting About Sexual and Gender-Based Violence}

Figure 2. Dendrogram of the Top-Down Hierarchical Classification on the Reasons for not Disclosing the Sexual and Gender-Based Violence

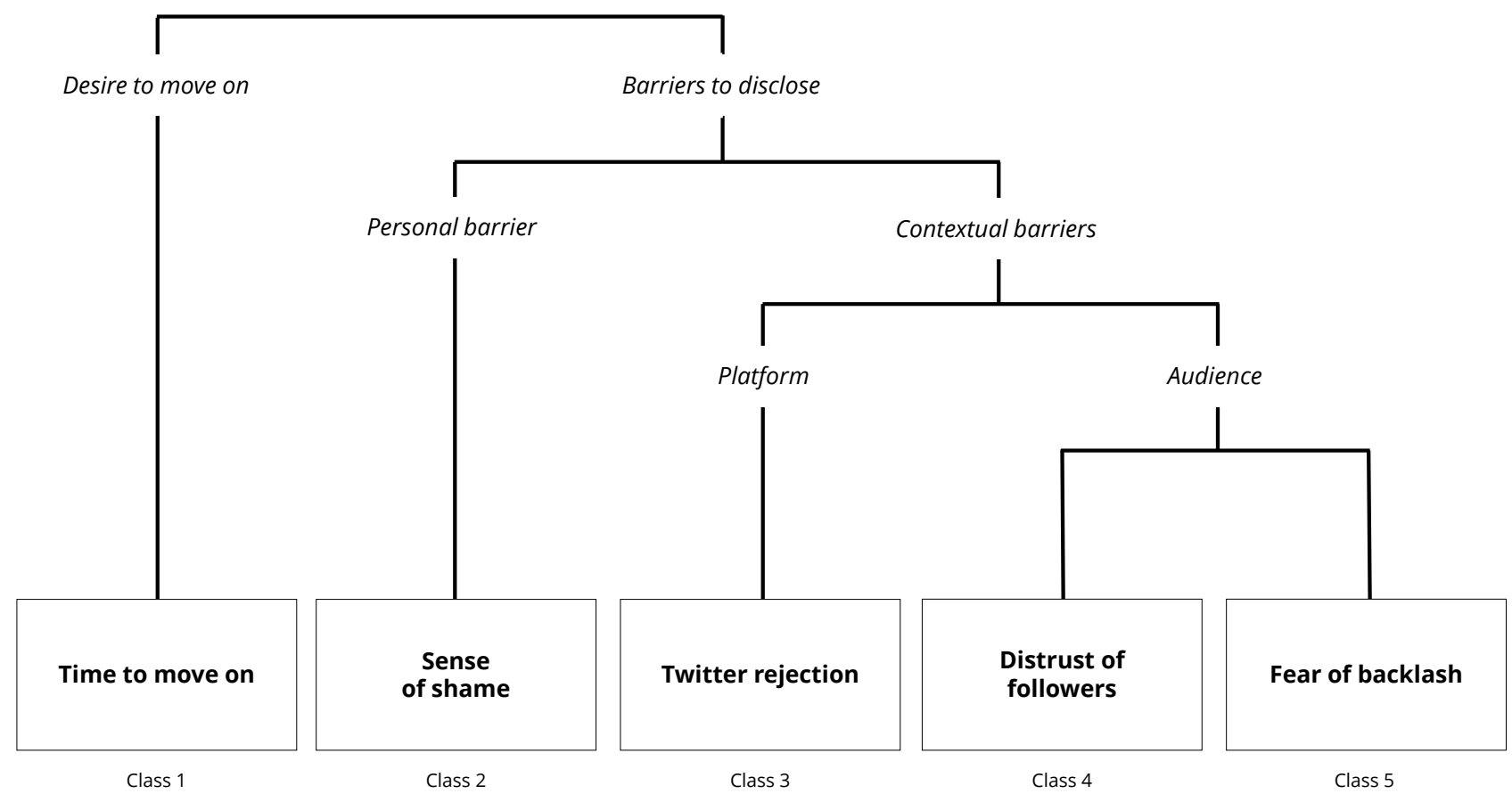

The corpus of answers by survivors who did not tweet about their experiences was composed of 2299 occurrences and contained 631 reduced forms. A simple text top-down hierarchical classification was carried out; $63.08 \%$ of answers to the question "Why did you not want to share on Twitter the gender-based and sexual violence you experienced?" were classified. Five classes were extracted. We labelled them: time to move on, sense of shame, Twitter rejection, distrust of followers, and fear of backlash. As for the previous corpus, we also labelled the 
associations between these classes via the analysis' dendrogram (figure 2). Below, the interpretations for each class are explained in more detail.

\section{Time to Move on}

The words significantly associated with the class were: violence (21.79), friend (10.03), metoo (10.03), mutual (10.03), leave (9.55), and time (6.16). The passive variable specifying the time that had passed since the event between 5 and 10 years (2.51) - was associated, but not significantly, with the class. The lexical universe bears on sexual and gender-based violence that the survivors considered to be in the past. They indicated that they had put it behind them, that they do not want to talk about it again for the time being. Several reasons are then given, such as, the fact that participants and the aggressor have mutual friends, or that they have managed to rebuild their lives following the victimisation. The discourse also reflects a set of considerations about the \#MeToo movement. The movement enabled certain survivors to better understand what they had experienced. A few characteristic segments: "Because I was not on twitter at the time, I reported it to the appropriate person (obstetrical violence reported to the management of the maternity ward) + less informed of these issues at the time + I underwent psychotherapy 'to leave it all behind me' so I didn't feel the need." and "It's thanks to the \#MeToo craze that I realised that I had been the victim of sexual violence. It took me time to realise."

\section{Sense of Shame}

The words significantly associated with the class were: shame (17.65), expose (9.55), social_media (6.07), and the passive variable referring to the time since the event - between 3 and 6 months (3.92). This lexical universe conveyed the shame felt by the survivors. Survivors did not wish to talk about the victimisation on Twitter so as not to expose it publicly. The sexual and gender-based violence had been experienced recently; for most it dated back to less than 6 months. A few characteristic segments are: "Shame, guilt, don't want to expose my life...", "I didn't have twitter at the time. And through shame I don't want to expose the events." and "Too personal, feeling of shame, and it was a long time ago. It's more important for me to be there for new victims."

\section{Twitter Rejection}

The words significantly associated with the class were: talk (21.08), twitter (10.79) and need (5.62). This lexical universe emphasised that Twitter is not a suitable place to talk about private events. Survivors preferred to talk to friends and relatives about the sexual and gender-based violence they experienced. A few characteristic segments: "It wasn't serious enough for me to mention it, and I feel that if I need help on this, there are better places than twitter to talk about it." and "I think that twitter is the worst place to talk about one's life."

\section{Distrust of Followers}

The words significantly associated with the class were: know (19.49), real_life (14.49), followers (11.70), personal (8.69), see (8.69), want (6.44), current (5.94), and story (4.58). This lexical universe speaks to survivors' cautiousness with regards to telling their followers a personal story. Followers are considered as strangers not to be trusted. A few characteristic segments: "Some of my followers know me in real life and do not know, I do not want to tell them in this way. Moreover, for me this is rather private and I do not want to share it with strangers, to see my story taken apart and judged (whether positively or negatively, no-one has the right to judge it, and writing it on Twitter makes people think they have the right to do it...)." and "Too personal, and I have very little interaction with my followers, that I do not know at all in real life."

\section{Fear of Backlash}

The words significantly associated with the class were: afraid (26.55), aggressor (25.86) and people (4.44). This lexical universe revolves around a fear of backlash. Survivors were afraid of being judged by others, or that the aggressor might try to get revenge or harm their reputation. Few characteristic segments: "I didn't do it because I don't have many followers so there would have been no impact. Moreover, there are followers who know me and my aggressor, I know that if I had told the facts they would have guessed who my aggressor was and would have been surprised (he is popular and does not correspond to the caricature that people have of a rapist). So I was 
afraid that some people would not believe me (which would have been painful) and that they would think that I was trying to slander the person. Lastly I could have been reduced to the status of victim or liar by a lot of people and I don't want these impacts on my life." and "Afraid of my words being turned against me by my aggressor (she is lying, she is mad, she wants revenge...). Afraid of the harassment which could follow."

\section{Discussion}

Being exposed to sexual and gender-based violence may have huge consequences for survivors. On the road to recovery, self-disclosure appears as one of the survivors' allies (Starzynski et al., 2005). This research therefore aimed at understanding why survivors of sexual and gender-based violence decided to share their stories on Twitter, and why others did not take the leap. Instead of relying on analyses of tweets, we directly investigated the survivors' perspective. Doing so, we explored reasons for disclosing and non-disclosing. In addition, we tried to establish a connection between two decision-making perspectives: the self-disclosure as well as collective action and social activism frameworks.

Our first research question revolved around the reasons for disclosing sexual and gender-based violence experienced on Twitter. Survivors expressed six motivations: give visibility to sexual and gender-based violence, support and contribute to the \#MeToo movement, talk about sexual and gender-based violence at work, change the public perceptions of sexual and gender-based violence, denounce the difficulty of filing a complaint, and overcome the victim blaming. These results are consistent with the notion of network-level reciprocal disclosures (Andalibi \& Forte, 2018; Gallagher et al., 2019). Survivors shared how the \#MeToo movement helped them to understand their situation and to self-disclose in-return: they realised that they are not alone, and that they were able to support the other survivors too. Another important outcome is that survivors were also motivated to denounce the rape culture surrounding sexual and gender-based violence. Participants highlighted instances of victim blaming and the difficulty of filing a complaint. The current judicial system is indeed struggling to convict aggressors (in France, less than 7\% of out-of-household rape are condemned, Bousquet et al., 2019), and the management of victims is considered as deplorable (Renard, 2018). Finally, the results showed that the classes extracted can be organised under two broad motivations: change society and support other survivors. This finding is in line with the study of Gueta et al. (2020) as well as key tenets of collective action and social activism frameworks. Indeed, manifestations of feminism on social network sites relies both on a politic of visibility and a politic of care. Survivors point out prejudices related to sexual and gender-based violence and take care of other survivors, giving them the courage to speak, which, in turn, also reinforces the movement (Clark-Parsons, 2021; Keller et al., 2018; Rentschler, 2014). That is, as proposed by the strategic dimension of the SIDE model (Klein et al., 2007). Participants, firstly, mobilised the support of society by trying to change the perception and the treatment of sexual and gender-based violence. Secondly, participants were able to consolidate and confirm their sense of belonging to the group of survivors: they gave their group a common fight visibility.

Our second research question dealt with the reasons for non-disclosing sexual and gender-based violence on Twitter. Survivors stressed five concerns: time to move on, sense of shame, Twitter rejection, distrust of followers, and fear of backlash. Doing so, survivors mainly expressed avoidance goals: by non-self-disclosing on Twitter, they avoid possible negative situations (Chaudoir \& Fisher, 2010). The Disclosure Decision-Making model (DDM) informs these results. The documented sense of shame - prevalent in the literature about sexual and genderbased violence (Alaggia, 2005) - can be associated with self-related or societal factors. Similarly, some survivors were unwilling to share their stories, neither in online nor offline contexts, and have indicated that it is time to move on (i.e., self-related factor). The reasons for non-disclosing also encompass the audience-related factor: survivors expected that sharing their stories on Twitter would have resulted in a backlash or harassment. They were wary of their followers too, which are viewed as unpredictable strangers (i.e., network-level factor). An important outcome is that the platform per se constituted an obstacle, highlighting the platform-related factor. Twitter was not perceived as a place for talking about intimate and private events. Finally, the analyses of the passive variables also suggested an influence of time that had passed since the event: the more recent the event, the more it was associated with shame (class 2, sense of shame; i.e., temporal factor). Conversely, as more time had passed, survivors reported having have gradually rebuilt their lives (class 1, time to move on).

A further important take-away of the findings is that the lack of anonymity on Twitter increased the perceived costs of sharing experiences. At the same time, by not being anonymous users can expose their personal stories 
in a powerful way, and, in doing so, act collectively. Thus, a lack of anonymity on a platform like Twitter may be seen as an opportunity for collective action's goals, but a limitation for self-disclosure's goals (Andalibi, 2020). To respond to our third research question, while the reasons for non-disclosing on Twitter can be informed by the self-disclosure framework (Andalibi, 2020; Andalibi \& Forte, 2018; Chaudoir \& Fisher, 2010), the reasons for disclosing on Twitter can be better explained by drawing on collective action and social activism frameworks (ClarkParsons, 2021; Keller et al., 2018; Klein et al., 2007; Rentschler, 2014). Taken together, we argue that in order to best understand why survivors do and do not share experiences of sexual and gender-based violence, selfdisclosure framework and collective action and social activism frameworks must be combined, and the phenomenon be investigated through a cross-media perspective. Social network sites can no longer be considered as homogeneous media: they differ in their architecture (Bossetta, 2018) and their norms (Waterloo et al., 2018) which may increase the context-dependence of self-disclosure. We encourage researchers to continue exploring how the type of social network sites could affect the way in which survivors are sharing sexual and gender-based violence. Although Twitter is well studied in the literature, some social network sites are yet unexplored. For instance, in April 2020 a new trend emerged on TikTok where survivors disclosed the outfit they were wearing when they were sexually assaulted. Social network sites have become part of our lives and, unfortunately, the stigma surrounding sexual and gender-based violence is still present; this research problem is thus more relevant than ever.

\section{Limitations}

These conclusions must be viewed in light of the following limitations. Firstly, the participants were all French, and there are cultural differences that we cannot account for. For example, Kim et al. (2011) have shown that people use social network sites for similar reasons, but that the weights places on these reasons may differ from one country to another. In addition, the perception of sexual and gender-based violence also differs between countries: the French culture emphasises seduction and the gallantry to define love; in a literary essay Rey-Robert (2019) explained how these traditions lead to a French rape culture which all the more justifies the rape. We therefore recommend conducting research in several countries to identify if these cultural differences influence our conclusions.

Secondly, although the ALCESTE method has some advantages, like reproducibility and transparency, other qualitative methods could be of interest. For example, ALCESTE analysis is blind to the data meaning, which is not the case of thematic analysis. We therefore support the recommendation of Lahlou (2011) to triangulate the methods, that is to say addressing the same research question with several methods. Future research should therefore pursue the investigation with mixed-methods, but also larger and more representative samples.

Thirdly, as suggested by the Disclosure Processes Model (Chaudoir \& Fisher, 2010), disclosing not only impacts the individuals, but also the macrosystem (i.e., culture and society). We therefore think that future research will need to explore the multilevel outcomes of disclosing on social network sites.

Finally, and most important for our purpose, this research cannot be generalised to other social network sites. Future research should compare several social network sites at the same time. To the best of our knowledge, Manikonda et al. (2018) are the only ones to have studied Twitter and Reddit in parallel.

\section{Acknowledgement}

We would first like to extend our gratitude to all the survivors who agreed to share their difficult experiences with us. Their participation is invaluable. We are also grateful to Twitter users who took the time to disseminate our study. On another note, we would like to acknowledge the valuable advice provided by Professor Olivier Klein. We, finally, thank the anonymous reviewers for pushing our thinking and thus improving the article.

\section{References}

Alaggia, R. (2005). Disclosing the trauma of child sexual abuse: A gender analysis. Journal of Loss and Trauma, 10(5), 453-470. https://doi.org/10.1080/15325020500193895 
Andalibi, N. (2020). Disclosure, privacy, and stigma on social media: Examining non-disclosure of distressing experiences. ACM Transactions on Computer-Human Interaction, 27(3), Article 18. https://doi.org/10.1145/3386600

Andalibi, N., \& Forte, A. (2018). Announcing pregnancy loss on Facebook: A decision-making framework for stigmatized disclosures on identified social network sites. In CHI '18: Proceedings of the $2018 \mathrm{CHI}$ Conference on Human Factors in Computing Systems (Paper no. 158). ACM. https://doi.org/10.1145/3173574.3173732

Andalibi, N., Haimson, O. L., De Choudhury, M., \& Forte, A. (2016). Understanding social media disclosures of sexual abuse through the lenses of support seeking and anonymity. In CHI '16: Proceedings of the $2016 \mathrm{CHI}$ Conference on Human Factors in Computing Systems (pp. 3906-3918). ACM. https://doi.org/10.1145/2858036.2858096

Bennett, W. L., \& Segerberg, A. (2012). The logic of connective action: Digital media and the personalization of contentious politics. Information, Communication \& Society, 15(5), 739-768.

https://doi.org/10.1080/1369118X.2012.670661

Bogen, K. W., Bleiweiss, K. K., Leach, N. R., \& Orchowski, L. M. (2019). \#MeToo: Disclosure and response to sexual victimization on Twitter. Journal of Interpersonal Violence. Advance online publication.

https://doi.org/10.1177/0886260519851211

Bogen, K. W., Bleiweiss, K. K., \& Orchowski, L. M. (2019). Sexual violence is \#NotOkay: Social reactions to disclosures of sexual victimization on Twitter. Psychology of Violence, 9(1), 127-137.

https://doi.org/10.1037/vio0000192

Bogen, K. W., Millman, C., Huntington, F., \& Orchowski, L. M. (2018). A qualitative analysis of disclosing sexual victimization by \#NotOkay during the 2016 presidential election. Violence and Gender, 5(3), 174-181. https://doi.org/10.1089/vio.2017.0053

Bossetta, M. (2018). The digital architectures of social media: Comparing political campaigning on Facebook, Twitter, Instagram, and Snapchat in the 2016 US election. Journalism \& Mass Communication Quarterly, 95(2), 471496. https://doi.org/10.1177/1077699018763307

Bousquet, D., Vouillot, F., Collet, M., \& Oderda, M. (2019). 1er état des lieux du sexisme en France [1st inventory of sexism in France] (No. 2018-01-07 STER 038). Haut Conseil à l'Egalité entre les femmes et les hommes. http://www.haut-conseil-egalite.gouv.fr/stereotypes-et-roles-sociaux/actualites/article/1 er-etat-des-lieux-dusexisme-en-france-lutter-contre-une-tolerance-sociale-qui

Carpenter, R. C. (2006). Recognizing gender-based violence against civilian men and boys in conflict situations. Security Dialogue, 37(1), 83-103. https://doi.org/10.1177/0967010606064139

Chaudoir, S. R., \& Fisher, J. D. (2010). The disclosure processes model: Understanding disclosure decision making and postdisclosure outcomes among people living with a concealable stigmatized identity. Psychological Bulletin, 136(2), 236-256. https://doi.org/10.1037/a0018193

Clark-Parsons, R. (2021). "I SEE YOU, I BELIEVE YOU, I STAND WITH YOU": \#MeToo and the performance of networked feminist visibility. Feminist Media Studies, 21(3), 362-380.

https://doi.org/10.1080/14680777.2019.1628797

Collective. (2018, January 9). Nous défendons une liberté d'importuner, indispensable à la liberté sexuelle [We defend a freedom to importune, which is indispensable to sexual freedom]. Le Monde.

https://www.lemonde.fr/idees/article/2018/01/09/nous-defendons-une-liberte-d-importuner-indispensable-a-laliberte-sexuelle_5239134_3232.html 
Davis, R. C., \& Brickman, E. (1996). Supportive and unsupportive aspects of the behavior of others toward victims of sexual and nonsexual assault. Journal of Interpersonal Violence, 11(2), 250-262.

https://doi.org/10.1177/088626096011002008

Djafarova, E., \& Rushworth, C. (2017). Exploring the credibility of online celebrities' Instagram profiles in influencing the purchase decisions of young female users. Computers in Human Behavior, 68, 1-7.

https://doi.org/10.1016/j.chb.2016.11.009

Donadio, R. (2017, October 18). \#BalanceTonPorc is France's \#MeToo. The Atlantic.

https://www.theatlantic.com/international/archive/2017/10/the-weinstein-scandal-seen-from-france/543315/

Finkelhor, D., Hotaling, G., Lewis, I. A., \& Smith, C. (1990). Sexual abuse in a national survey of adult men and women: Prevalence, characteristics, and risk factors. Child Abuse \& Neglect, 14(1), 19-28.

https://doi.org/10.1016/0145-2134(90)90077-7

Gallagher, R. J., Stowell, E., Parker, A. G., \& Foucault Welles, B. (2019). Reclaiming stigmatized narratives: The networked disclosure landscape of \#MeToo. In Proceedings of the ACM on Human-Computer Interaction (Vol. 3, Article 96). ACM. https://doi.org/10.1145/3359198

Gueta, K., Eytan, S., \& Yakimov, P. (2020). Between healing and revictimization: The experience of public selfdisclosure of sexual assault and its perceived effect on recovery. Psychology of Violence, 10(6), 626-637. https://doi.org/10.1037/vio0000309

Hlavka, H. R. (2017). Speaking of stigma and the silence of shame: Young men and sexual victimization. Men and Masculinities, 20(4), 482-505. https://doi.org/10.1177/1097184X16652656

Keller, J., Mendes, K., \& Ringrose, J. (2018). Speaking 'unspeakable things': Documenting digital feminist responses to rape culture. Journal of Gender Studies, 27(1), 22-36.

https://doi.org/10.1080/09589236.2016.1211511

Kim, Y., Sohn, D., \& Choi, S. M. (2011). Cultural difference in motivations for using social network sites: A comparative study of American and Korean college students. Computers in Human Behavior, 27(1), 365-372. https://doi.org/10.1016/j.chb.2010.08.015

Klein, O., Spears, R., \& Reicher, S. (2007). Social identity performance: Extending the strategic side of SIDE. Personality and Social Psychology Review, 11(1), 28-45. https://doi.org/10.1177/1088868306294588

Lahlou, S. (2011). Text mining methods: An answer to Chartier and Meunier. Papers on Social Representations, 20(2), Article 38. https://psr.iscte-iul.pt/index.php/PSR/article/view/453

Lea, M., \& Spears, R. (1991). Computer-mediated communication, de-individuation and group decision-making. International Journal of Man-Machine Studies, 34(2), 283-301. https://doi.org/10.1016/0020-7373(91)90045-9

Lonsway, K. A., \& Fitzgerald, L. F. (1994). Rape myths: In review. Psychology of Women Quaterly, 18(2), 133-164. https://doi.org/10.1111/j.1471-6402.1994.tb00448.x

Lonsway, K. A., \& Fitzgerald, L. F. (1995). Attitudinal antecedents of rape myth acceptance: A theoretical and empirical reexamination. Journal of Personality and Social Psychology, 68(4), 704-711.

https://doi.org/10.1037/0022-3514.68.4.704

Manikonda, L., Beigi, G., Liu, H., \& Kambhampati, S. (2018). Twitter for sparking a movement, Reddit for sharing the moment: \#metoo through the lens of social media. ArXiv:1803.08022 [Cs]. http://arxiv.org/abs/1803.08022

Onwuachi-Willig, A. (2018). What about \#UsToo: The invisibility of race in the \#MeToo movement. The Yale Law Journal, 128, 105-120. https://www.yalelawjournal.org/forum/what-about-ustoo 
Papacharissi, Z. (2016). Affective publics and structures of storytelling: Sentiment, events and mediality. Information, Communication \& Society, 19(3), 307-324. https://doi.org/10.1080/1369118X.2015.1109697

Posey, C., Lowry, P. B., Roberts, T. L., \& Ellis, T. S. (2010). Proposing the online community self-disclosure model: The case of working professionals in France and the UK who use online communities. European Journal of Information Systems, 19(2), 181-195. https://doi.org/10.1057/ejis.2010.15

Postmes, T., Spears, R., \& Lea, M. (1998). Breaching or building social boundaries? SIDE-effects of computermediated communication. Communication Research, 25(6), 689-715.

https://doi.org/10.1177/009365098025006006

Ratinaud, P. (2009). IRaMuTeQ: Interface de R pour les Analyses Multidimensionnelles de Textes et de Questionnaires [IRaMuTeQ: R interface for multidimensional analysis of texts and questionnaires]. http://www.iramuteq.org

Reinert, M. (1983). Une méthode de classification descendante hiérarchique: Application à l'analyse lexicale par contexte [A top-down hierarchical classification method: application to lexical analysis by context]. Cahiers de I'Analyse Des Données, 8(2), 187-198. http://www.numdam.org/item/CAD_1983_8_2_187_0/

Reinert, M. (1986). Un logiciel d'analyse lexicale [A lexical analysis software]. Cahiers de l'analyse Des Données, 11(4), 471-481. http://www.numdam.org/item/CAD_1986_11_4_471_0/

Reinert, M. (1987). Classification Descendante Hierarchique et Analvse Lexicale par Contexte-Application au Corpus des Poesies D'A. Rimbaud [Top-down hierarchical classification and lexical analysis by contextApplication to the corpus of Poems of A. Rimbaud]. Bulletin of Sociological Methodology, 13(1), 53-90. https://doi.org/10.1177/075910638701300107

Reinert, M. (2002). Alceste: Un logiciel d'aide pour l'analyse de discours [Alceste: a support software for discourse analysis]. Notice simplifiée (de la version de base commune aux versions 4.x). http://www.ling.uqam.ca/forum/satoman/images/AlcesteNoticeSimplifiee.pdf

Renard, N. (2018). En finir avec la culture du viol [Bring an end to the rape culture]. Les Petits Matins.

Rentschler, C. A. (2014). Rape culture and the feminist politics of social media. Girlhood Studies, 7(1), 65-82. https://doi.org/10.3167/ghs.2014.070106

Rey-Robert, V. (2019). Une culture du viol à la française: Du «troussage de domestique » à la « liberté d'importuner » [A French rape culture: from 'domestic troussage' to 'freedom to importune']. Libertalia.

Schonhardt-Bailey, C., Yager, E., \& Lahlou, S. (2012). Yes, Ronald Reagan's rhetoric was unique-but statistically, how unique? Presidential Studies Quarterly, 42(3), 482-513. https://doi.org/10.1111/j.1741-5705.2012.03990.x

Similarweb. (2019). Top Social Network Websites in the world. https://www.similarweb.com/fr/topwebsites/category/internet-and-telecom/social-network

Spears, R. (2017). Social identity model of deindividuation effects. The International Encyclopedia of Media Effects. John Wiley \& Sons, Inc. https://doi.org/10.1002/9781118783764.wbieme0091

Starzynski, L. L., Ullman, S. E., Filipas, H. H., \& Townsend, S. M. (2005). Correlates of women's sexual assault disclosure to informal and formal support sources. Violence and Victims, 20(4), 417-432.

https://doi.org/10.1891/0886-6708.20.4.417

Stenberg, S. J. (2018). "Tweet me your first assaults": Writing shame and the rhetorical work of\# NotOkay. Rhetoric Society Quarterly, 48(2), 119-138. https://doi.org/10.1080/02773945.2017.1402126 
Suarez, E., \& Gadalla, T. M. (2010). Stop blaming the victim: A meta-analysis on rape myths. Journal of Interpersonal Violence, 25(11), 2010-2035. https://doi.org/10.1177/0886260509354503

Swim, J. K., \& Hyers, L. L. (1999). Excuse me-What did you just say?!: Women's public and private responses to sexist remarks. Journal of Experimental Social Psychology, 35(1), 68-88. https://doi.org/10.1006/jesp.1998.1370

Tenaglia, A. (2019, September 25). Sandra Muller, à l'origine de \#Balancetonporc, condamnée pour diffamation [Sandra Muller, the founder of \#Denounceyourpig, convicted for defamation]. Le Parisien.

http://www.leparisien.fr/societe/sandra-muller-a-l-origine-de-balancetonporc-condamnee-pour-diffamation-2509-2019-8159496.php

Waterloo, S. F., Baumgartner, S. E., Peter, J., \& Valkenburg, P. M. (2018). Norms of online expressions of emotion: Comparing Facebook, Twitter, Instagram, and WhatsApp. New Media \& Society, 20(5), 1813-1831. https://doi.org/10.1177/1461444817707349

Wright, S. C., Taylor, D. M., \& Moghaddam, F. M. (1990). Responding to membership in a disadvantaged group: From acceptance to collective protest. Journal of Personality and Social Psychology, 58(6), 994-1003.

https://doi.org/10.1037/0022-3514.58.6.994 


\section{Correspondence to:}

Alexandra Masciantonio

Université de Lorraine

lle du saulcy

Metz, F-57000

France

Email: alexandra.masciantonio(at)univ-lorraine.fr

Editorial record: First submission received on September 9, 2020. Revisions received on February 3, 2021 and April 1, 2021. Accepted for publication on April 29, 2021.

Editor in charge: Alexander Schouten

\section{About Authors}

Alexandra Masciantonio is a Ph.D. student with a doctoral grant at the University of Lorraine (psychology department, France). Relying on a cross-platform perspective, her works are built around two research questions. The first concerns why and how people use social network sites (users' motivations, norms of expression, selfdisclosure, collective action). The second deals with the consequences of the utilization of social network sites on well-being.

Sandy Schumann is a Lecturer (Assistant Professor) and the Postgraduate Tutor at University College London, Department of Security and Crime Science. Her research examines risk factors of radicalisation, extreme political attitudes, as well as hate crime prevention. She studies these phenomena 'online' as well as 'offline'. She is keen to translate her research into policy and practice. Doing so, she advises governments (e.g., UK Commission on Countering Extremism, UAE Ministry of Culture and Knowledge Development) and collaborates with civil society organisations to conduct impact evaluations.

David Bourguignon is Professor in Social Psychology at the University of Lorraine (Metz, France) and visiting professor at the Catholic University of Louvain (Belgium). His research focuses on intergroup relations and more particularly on the stigmatization processes of low status groups. In this perspective, he is also interested in social and professional integration policies as well as policies for the prevention of discrimination and the promotion of diversity.

(C) Author(s). The articles in Cyberpsychology: Journal of Psychosocial Research on Cyberspace are open access articles licensed under the terms of the Creative Commons BY-NC-ND 4.0 International License which permits unrestricted, non-commercial use, distribution and reproduction in any medium, provided the work is properly cited. 